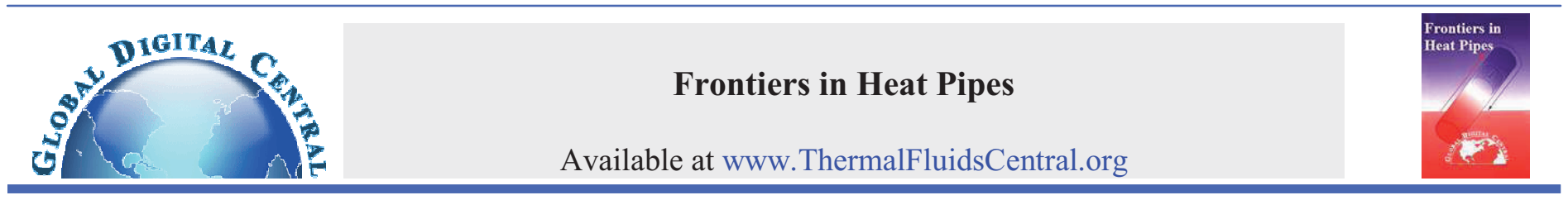

\title{
HEAT PIPE SIMULATION UNDER CRITICAL CONDITIONS
}

\author{
Taoufik Brahim,* Abdelmajid Jemni \\ Laboratory of Thermal and Energy Systems Study (LESTE), National School of Engineers of Monastir (ENIM), \\ University of Monastir (UM), Road Ibn Jazzar 5019 Monastir, Tunisia
}

\begin{abstract}
Flow, heat and mass transfer in heat pipes has been studied extensively. This is due to the increasing need in understanding the complicated transport process for application of diverse fields. Recently one of the heat pipes which aroused the interest of research are the three dimensional heat pipes which incorporates the phase change mechanisms at the liquid and vapour interface. In this paper, an originally three-dimensional steady state model is developed coupling the hydrodynamic and thermal models in sintered heat pipe in cylindrical polar coordinate. The model predicts the heat pipes behaviors under critical conditions were a high heat input is exposed to its evaporator region. Such study has not been well investigated before and can be useful for academic, engineering and industrial purposes. Compared with its normal working conditions were heat pipes limits are not reached, the results illustrate well the function of the heat pipe and the circulation of the working fluid inside the heat pipe regions. Results show also that, for high heat input the circumferential velocity components increase specially in the liquid-vapor interface and the tangential velocity component has a significant effect on the phase change phenomena.

Keywords: Three-dimensional, Conventional Heat Pipe, Numerical Simulation, Visualization.
\end{abstract}

\section{INTRODUCTION}

Heat pipes behavior under critical conditions were it is exposed to higher heat fluxes or from the frozen state has been not well investigated. Deverall et al (1970) studied the transient behavior of water and metal liquid heat pipes from the frozen state. They concluded that successful star-up for higher heat input was possible if the heat rejection in the condenser region was low enough to enable the heat to melt the working fluids in the condenser and allow liquid to return to the evaporator. Issacci et al (1988) studied the transient behavior of the vapor flow in a rectangular heat pipe. Flow reversal was detected in the condenser and adiabatic regions with water as the working fluid. However, only some axial and radial velocity profiles were presented in the paper. They detected that for high input heat flux, a reverse flow in both adiabatic and condenser region may occurs and suggested that a parametric study in needed to explore the reverse flow versus design parameters like the evaporator, condenser, adiabatic and total length of the heat pipe for different input heat fluxes and condenser temperatures. Reverse flow in the condenser section was also observed by (Ooijen and Hoogindoorn 1979) who performed an experimental and numerical studies on heat pipe vapor flow, their analysis was confined to a steady state, incompressible, two dimensional flows. They also found that the total pressure drop over the heat pipe, for high radial Reynolds numbers, was higher than that approximated by a Poiseuille flow model. The numerical model developed for incompressible, steady state, two dimensional vapor flows in a heat pipe by (Banskton and Smith 1972 and 1973) show that flow reversal in the condenser can occurs for radial Reynolds numbers larger than two. Indication of a reverse flow is important in design of a heat pipe in calculating the shear forces acting on the wick structure and affects the entrainment limit. Indeed, shear force existing at the liquid-vapor interface may tear the liquid from the wick surface and entrain it into the vapor flow steam. This phenomenon limits the heat transport capability of the device. Considering a wick structure of low pore dimensions, the shear forces could very low.

A three dimensional numerical modeling of circumferentially heated and block heated heat pipes was presented by Faghri (1991) to study the startup behavior of high-temperature heat pipes from the frozen state for various heat loads and input locations. Zhu and Vafai (1998) analyzed a three dimensional vapor and liquid flow in an asymmetric flat plate heat pipe. They studied the vapor flow by finite element method using FIDAP code. Vadakkan and al $(2003,2004)$ developed a three-dimensional numerical model to study the performance of flat heat pipes with multiple discrete heat sources. The effects of heat source strength and separation on steady as well as transient performance were studied. A transient, three-dimensional model for thermal transport in flat heat pipes considering wick microstructure effects is developed recently (Carbajal and al 2007). The Marangoni convection effects and the accommodation coefficient during phase change at the liquid-vapor interface are investigated for a heat pipe with a screen-mesh wick. Xiao and Faghri (2008) developed also a three-dimensional model for flat heat pipe which accounted for heat conduction in the wall and fluid flow in the vapor core and porous wicks.

Most three-dimensional previous studies are performed for flat heat pipe due their applications in electronic cooling or/and spacecraft radiator segments. However, convectional heat pipes have many industrial applications such as heat exchanger systems and a three dimensional analysis with own tool simulation is necessary to predict the heat pipe behavior for the complexity of the system.

\footnotetext{
" Corresponding author. Email: taoufik.brahim@yahoo.fr
} 
In this paper, a three dimensional model has been performed in cylindrical polar coordinate for the conventional heat pipe coupling the heat pipe three regions (wall, wick, vapor).

A code written with FORTRAN was developed using the finite volume method to solve the governing equations and the wick-level micromodel using the kinetic theory of gases is utilized only to correct the phase change mass flow rates at the liquid-vapor interface (Eq. (14)) in the macro-model.

The Navier-Stokes equations along with the energy equation are solved numerically. Darcy-Brinkman-Forchheimer model is used in the wick structure and evaporation-condensation at the liquid-vapor interface is modeled using the gas kinetic theory model. The heat pipe is exposed to normal and critical heat input to visualize the different velocities within and the results illustrate well the function of the heat pipe and the circulation of the working fluid inside the heat pipe regions.

\section{NUMERICAL MODEL}

In cylindrical polar coordinate system, the axis " $\mathrm{z} "$ is the axis of symmetry lies along the centre of the heat pipe and taken parallel to the base flow velocity. " $r$ " is the radial distance and " $\varphi$ " is the azimuthal angle. A schematic description of the cylindrical heat pipe is shown in the Fig.1:

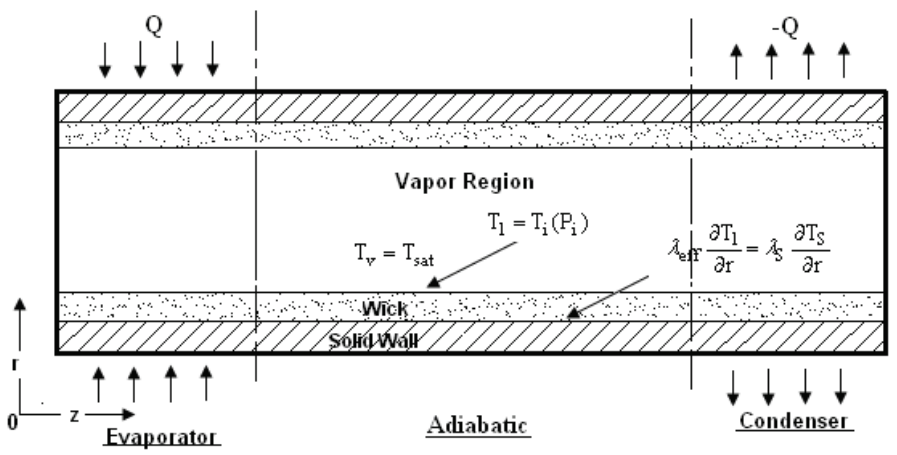

Fig. 1 Heat pipe description

The temperature distribution is a function of $(r, z)$. The Navier-Stokes equations, the energy equation and the continuity equation for the case of the steady axi-symetric motion of an incompressible fluid in a porous media which accounts for the boundary and inertial effects are (Ranjan and al 2011):

\section{- Continuity equation:}

$$
\frac{\partial \mathrm{U}_{\mathrm{r}}}{\partial \mathrm{r}}+\frac{\mathrm{U}_{\mathrm{r}}}{\mathrm{r}}+\frac{\partial \mathrm{U}_{\mathrm{z}}}{\partial \mathrm{z}}=0
$$

\section{- Navier-Stokes equations:}

$$
\begin{aligned}
& \rho_{\mathrm{l}}\left(\mathrm{U}_{\mathrm{r}} \frac{\partial \mathrm{U}_{\mathrm{z}}}{\partial \mathrm{r}}+\mathrm{U}_{\mathrm{z}} \frac{\partial \mathrm{U}_{\mathrm{z}}}{\partial \mathrm{z}}\right)=-\varepsilon \frac{\partial \mathrm{P}}{\partial \mathrm{z}}+\mu\left(\frac{\partial^{2} \mathrm{U}_{\mathrm{z}}}{\partial \mathrm{r}^{2}}+\frac{1}{\mathrm{r}} \frac{\partial \mathrm{U}_{\mathrm{z}}}{\partial \mathrm{r}}+\frac{\partial^{2} \mathrm{U}_{\mathrm{z}}}{\partial \mathrm{z}^{2}}\right) \\
& -\frac{\mu \varepsilon}{\mathrm{K}} \mathrm{U}_{\mathrm{z}}-\frac{\mathrm{C}_{\mathrm{F}}}{\sqrt{\mathrm{K}}}|\mathrm{V}| \mathrm{U}_{\mathrm{z}}
\end{aligned}
$$

$$
\begin{aligned}
& \rho_{1}\left(\mathrm{U}_{\mathrm{r}} \frac{\partial \mathrm{U}_{\mathrm{r}}}{\partial \mathrm{r}}-\frac{\mathrm{U}_{\phi}^{2}}{\mathrm{r}}+\mathrm{U}_{\mathrm{z}} \frac{\partial \mathrm{U}_{\mathrm{r}}}{\partial \mathrm{z}}\right)=-\varepsilon \frac{\partial \mathrm{P}}{\partial \mathrm{r}} \\
& +\mu\left(\frac{\partial^{2} \mathrm{U}_{\mathrm{r}}}{\partial \mathrm{r}^{2}}+\frac{1}{\mathrm{r}} \frac{\partial \mathrm{U}_{\mathrm{r}}}{\partial \mathrm{r}}-\frac{\mathrm{U}_{\mathrm{r}}}{\mathrm{r}^{2}}+\frac{\partial^{2} \mathrm{U}_{\mathrm{r}}}{\partial \mathrm{z}^{2}}\right)-\frac{\mu \varepsilon}{\mathrm{K}} \mathrm{U}_{\mathrm{r}}-\frac{\mathrm{C}_{\mathrm{F}}}{\sqrt{\mathrm{K}}}|\mathrm{V}| \mathrm{U}_{\mathrm{r}} \\
& \rho_{\mathrm{l}}\left(\mathrm{U}_{\mathrm{r}} \frac{\partial \mathrm{U}_{\phi}}{\partial \mathrm{r}}+\frac{\mathrm{U}_{\mathrm{r}} \mathrm{U}_{\phi}^{2}}{\mathrm{r}}+\mathrm{U}_{\mathrm{z}} \frac{\partial \mathrm{U}_{\phi}}{\partial \mathrm{z}}\right)=\mu\left(\frac{\partial^{2} \mathrm{U}_{\phi}}{\partial \mathrm{r}^{2}}+\frac{1}{\mathrm{r}} \frac{\partial \mathrm{U}_{\phi}}{\partial \mathrm{r}}-\frac{\mathrm{U}_{\phi}}{\mathrm{r}^{2}}+\frac{\partial^{2} \mathrm{U}_{\phi}}{\partial \mathrm{z}^{2}}\right) \\
& -\frac{\mu \varepsilon}{\mathrm{K}} \mathrm{U}_{\phi}-\frac{\mathrm{C}_{\mathrm{F}}}{\sqrt{\mathrm{K}}}|\mathrm{V}| \mathrm{U}_{\phi}
\end{aligned}
$$

- Energy equation:

$$
\mathrm{U}_{\mathrm{r}} \frac{\partial \mathrm{T}}{\partial \mathrm{r}}+\mathrm{U}_{\mathrm{z}} \frac{\partial \mathrm{T}}{\partial \mathrm{z}}=\alpha_{\mathrm{eff}}\left(\frac{\partial^{2} \mathrm{~T}}{\partial \mathrm{r}^{2}}+\frac{1}{\mathrm{r}} \frac{\partial \mathrm{T}}{\partial \mathrm{r}}+\frac{\partial^{2} \mathrm{~T}}{\partial \mathrm{z}^{2}}\right)
$$

where $U_{z}, U_{r}, U_{\varphi}$ is the axial, radial and azimuthal velocity components respectively. $|\mathrm{V}|=\sqrt{\mathrm{U}_{\mathrm{r}}^{2}+\mathrm{U}_{\mathrm{z}}^{2}+\mathrm{U}_{\varphi}^{2}}$, and $\sqrt{\mathrm{K}}$ is the effective pore diameter in the porous media. $\mathrm{C}_{\mathrm{F}}$ is the Egun's constant which value is approximately 0.55 .

$\alpha_{\text {eff }}=\frac{\lambda_{\text {eff }}}{\varepsilon \rho_{1} C_{\text {pl }}}$ is the effective thermal diffusivity.

$\mathrm{K}$ is the permeability of the sintered powder wick given by (Chi 1976):

$$
\mathrm{K}=\frac{\mathrm{r}_{\mathrm{s}}^{2} \varepsilon^{3}}{37.5(1-\varepsilon)^{2}}
$$

where, $r_{c}=0.41 r_{s}$ represent the effective capillary radius.

In the vapor core, the equations governing the heat and mass transfers are given by considering the above equation in which the permeability and the porosity are respectively taken equal to infinity and one. Also the other thermo-physical properties like density, thermal conductivity and viscosity are changed to that of the vapor.

The heat pipe wick (sintered powder wick) was assumed to be a homogeneous and isotropic porous medium (constant porosity and permeability). The dissipation effects were neglected (Faghri 1995). The advantage of the sintered powder wick is its ability to handle higher heat flux. Indeed, typical sintered wicks handle $50 \mathrm{~W} / \mathrm{cm} 2$, and have been tested to up $250 \mathrm{~W} / \mathrm{cm}^{2}$.

$\lambda_{\text {eff }}=\frac{\lambda_{1}\left[\left(2 \lambda_{1}+\lambda_{\mathrm{w}}\right)-2(1-\varepsilon)\left(\lambda_{1}-\lambda_{\mathrm{w}}\right]\right.}{\left[\left(2 \lambda_{1}+\lambda_{\mathrm{s}}\right)+(1-\varepsilon)\left(\lambda_{1}-\lambda_{\mathrm{w}}\right]\right.}$

$\lambda_{\text {eff }}$ is the effective thermal conductivity in the wick structure (Chi 1976). In the solid region, $\lambda_{\text {eff }}$ become $\lambda_{\mathrm{s}}$.

$\lambda_{\mathrm{w}}$ is the is the thermal conductivity of the wick material (copper).

\subsection{Boundary Conditions}

- $\quad$ At liquid-solid wall interface:

$$
\left\{\begin{array}{l}
\mathrm{U}_{\mathrm{z}}=\mathrm{U}_{\mathrm{r}}=\mathrm{U}_{\varphi}=0 \\
\lambda_{\mathrm{eff}} \frac{\partial \mathrm{T}_{1}}{\partial \mathrm{r}}=\lambda_{\mathrm{s}} \frac{\partial \mathrm{T}_{\mathrm{s}}}{\partial \mathrm{r}}
\end{array}\right.
$$


- At heat pipe ends $z=0$ and $z=L$ :

$\left\{\begin{array}{l}\mathrm{U}_{\mathrm{z}}=\mathrm{U}_{\mathrm{r}}=\mathrm{U}_{\varphi}=0 \\ \frac{\partial \mathrm{T}_{1}}{\partial \mathrm{z}}=0\end{array}\right.$

- At liquid-vapor interface:

$\left\{\begin{array}{l}\mathrm{U}_{\mathrm{r}}=\mathrm{V}_{\mathrm{i}} ; \mathrm{U}_{\mathrm{z}}=\mathrm{U}_{\varphi}=0 \\ \mathrm{~T}_{1}=\mathrm{T}_{\mathrm{i}}\left(\mathrm{P}_{\mathrm{i}}\right)\end{array}\right.$

A constant heat flux "Q" is exposed at the outer surface of the heat pipe wall; positive in the evaporator region and negative in the condenser region:

$-\lambda_{\mathrm{s}} \frac{\partial \mathrm{T}_{\mathrm{s}}}{\partial \mathrm{r}}=\mathrm{Q}$

- At heat pipe ends $\mathrm{z}=0$ and $\mathrm{z}=\mathrm{L}$ :

$\frac{\partial \mathrm{T}_{\mathrm{s}}}{\partial \mathrm{z}}=0$

The energy balance at the liquid /vapor interface yields:

$\rho_{1} \mathrm{~V}_{\mathrm{i}} \mathrm{C}_{\mathrm{pl}} \mathrm{T}_{\mathrm{i}}-\lambda_{\mathrm{l}} \frac{\partial \mathrm{T}_{1}}{\partial \mathrm{r}}=\rho_{\mathrm{v}} \mathrm{V}_{\mathrm{i}} \mathrm{C}_{\mathrm{pv}} \mathrm{T}_{\mathrm{i}}-\lambda_{\mathrm{v}} \frac{\partial \mathrm{T}_{\mathrm{v}}}{\partial \mathrm{r}}+\rho_{\mathrm{v}} \mathrm{V}_{\mathrm{i}} \mathrm{h}_{\mathrm{fg}}$

$\mathrm{V}_{\mathrm{i}}$ is the injection velocity corrected until the mass flux residual reduces to an acceptable value. To account for corrected injection velocity at the liquid vapor interface, the evaporation and condensation mass fluxes are calculated from the kinetic theory of gases (Eames and al 1997).

$\mathrm{V}_{\mathrm{i}}=\frac{\mathrm{a}_{\mathrm{cc}}}{\rho_{\mathrm{v}}}\left(\frac{\mathrm{M}}{2 \pi \mathrm{T}_{\mathrm{i}}}\right)^{1 / 2}\left[\mathrm{P}_{\mathrm{i}}\left(\mathrm{T}_{\mathrm{i}}\right)-\mathrm{P}_{\mathrm{v}}\right]$

where " $\mathrm{a}_{\mathrm{cc}}$ "is the accommodation coefficient assumed to unity, " $\mathrm{M}$ " is mass molar and " $T_{i}$ " is the liquid interface temperature calculated by the Clausius-Clapeyron equation as follow:

$\frac{\mathrm{R}}{\mathrm{h}_{\mathrm{fg}}} \ln \left(\frac{\mathrm{P}_{\mathrm{i}}}{\mathrm{P}_{0}}\right)=\frac{1}{\mathrm{~T}_{0}}-\frac{1}{\mathrm{~T}_{\mathrm{i}}}$

Since the density of the vapor is linked to saturation temperature and vapor pressure to surface tension, an iterative schedule is then added to calculate the vapor saturation temperature.

The simulations were done for water as working fluid. The reference pressure and temperature are respectively $\mathrm{P}_{0}=1.019710^{5} \mathrm{~Pa}$ and $\mathrm{T}_{0}=$ $273.15 \mathrm{~K}$. The effect of wall temperature gradient is neglected and the heat pipe characterizations were summered in the Table 1.

The above system of equations (Eq. (1-5)), are transformed to dimensional form to simplify the resolution. Therefore, all the calculated velocity components are transformed in dimensional form: $\mathrm{U} / \mathrm{V}_{\mathrm{i}}$ (Carbajal and al 2007).
Table 1: Heat pipe specific characterizations

\begin{tabular}{|l|l|}
\hline $\begin{array}{l}\text { HP container material } \\
\text { Copper: } \lambda_{\mathrm{s}}=387.6 \mathrm{~W} / \mathrm{mK}\end{array}$ & $\begin{array}{l}\text { porous media: } \\
\text { Sintered powder wick }\end{array}$ \\
\hline Wick thickness: $1 \mathrm{~mm}$ & Vapor diameter: $0.0127 \mathrm{~m}$ \\
\hline HP length: $1 \mathrm{~m}$ & Porosity: 0.5 \\
\hline Condenser length: $0.4 \mathrm{~m}$ & Evaporator length: $0.4 \mathrm{~m}$ \\
\hline Permeability: $0.5810^{-11} \mathrm{~m}^{2}$ & Working fluid: Distilled water \\
\hline Vapor conductivity: & Liquid density: \\
$\lambda_{\mathrm{v}}=0.0251 \mathrm{~W} / \mathrm{mK}$ & $\rho_{1}=960.63 \mathrm{~kg} / \mathrm{m}^{3}$ \\
\hline Vapor density: & Surface tension: \\
$\rho_{\mathrm{v}}=0.59 \mathrm{~kg} / \mathrm{m}^{3}$ & $\sigma=5.8910^{-2} \mathrm{Pam}$ \\
\hline $\begin{array}{l}\text { Heat latent: } \\
\mathrm{h}_{\mathrm{fg}}=2251.2 \mathrm{~kJ} / \mathrm{kg}\end{array}$ & Liquid heat capacity: \\
\hline
\end{tabular}

\section{RESULTS AND DISCUSSION}

The code developed to solve the above system of coupled equations used the finite volume method with the power law scheme and SIMPLE algorithm. Many numerical tests were made in order to establish the best grid size for the numerical calculations by varying the number of control volume in both directions. The results indicated that a grid size of $12 \times 360 \times 262$ and $62 \times 360 \times 262$ (radial, azimuthal, axial) was good enough for the present calculations in the porous media and the vapor regions respectively.

To make sure of the validity of our computational code, a comparison was made in two dimensional analyses with the analytical earlier work of Zhu and Vafai (1999) and the numerical results of Tournier and ElGenk (1994) since luck of three-dimensional studies on conventional heat pipe founded in the literature. In Fig. 2 and Fig. 3 the outer wall surface temperature and the pressure profiles within the wick structure and the vapour phase are compared with both numerical and analytical previous works. A good agreement is found.

Fig. 4 compares the velocity profiles in the liquid and the vapor regions. The positive velocity value denotes that the flow is from the evaporator to the condenser region and the negative velocity value denotes that the flow is from the condenser to the evaporator region. A good agreement is found too when considering the two dimensional model with low Reynolds number.

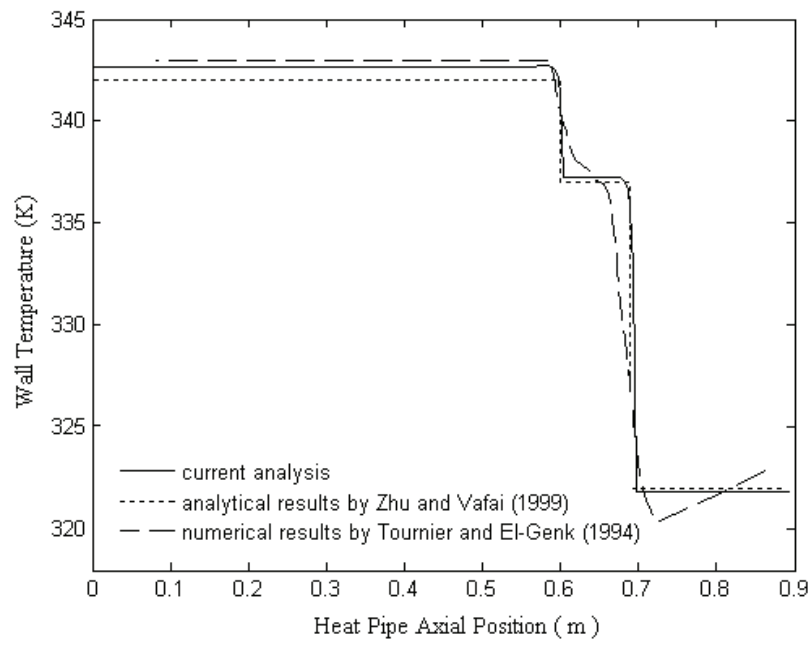

Fig. 2 Wall surface temperature distribution compared with previous works 


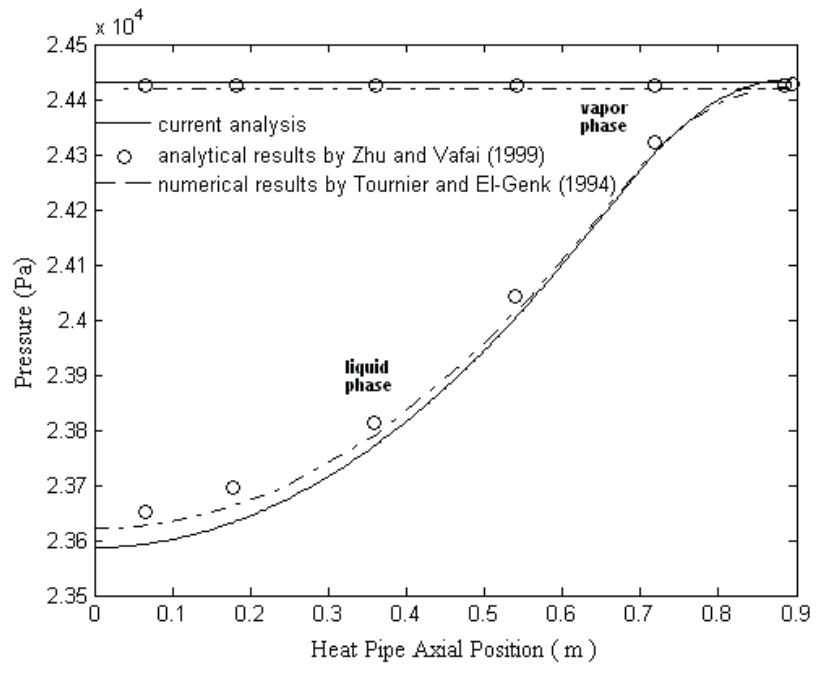

Fig. 3 Pressure profiles in the liquid and the vapor regions of heat pipe compared with previous works

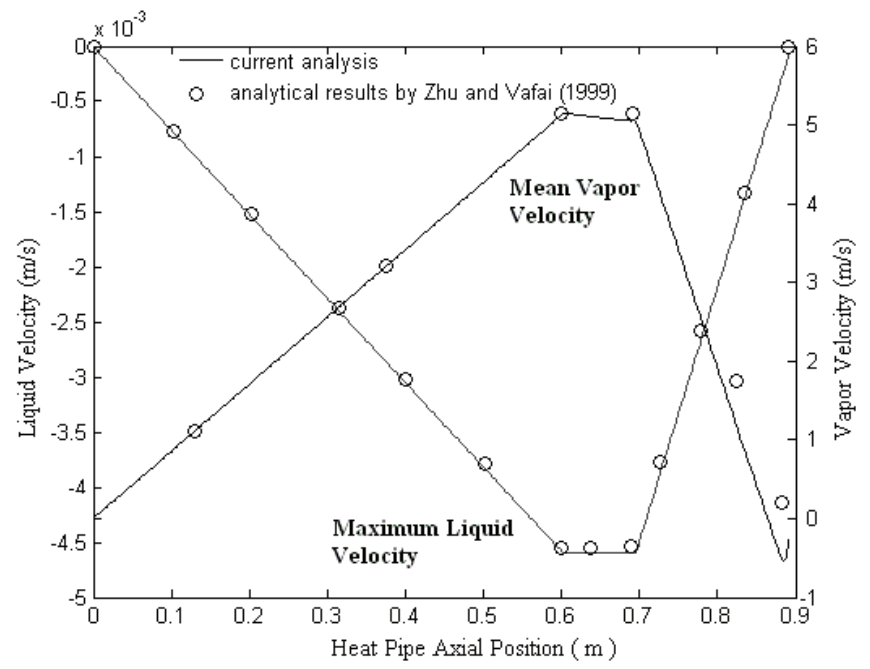

Fig. 4 Validation results of maximum liquid velocity and mean vapor velocity in bidirectional analysis.

Fig.5 and Fig.6 shows the dimensional velocity profile in the vapor region as seen looking down the pipe axis. NZ means the number of grid points along the heat pipe axial direction (same method used by Faghri 1991). The Fig.5 shows that for a normal heat input/output of $5000 \mathrm{~W} / \mathrm{m} 2$, a symmetry profiles can be concluded in the evaporator and the condenser regions and fully developed profile in the adiabatic region. The maximum radial vapor velocity in the evaporator region is about $8.16910^{-4} \mathrm{~m} / \mathrm{s}$ and about $0.001 \mathrm{~m} / \mathrm{s}$ in the condenser region and slows in the adiabatic region $\left(1.8010^{-4} \mathrm{~m} / \mathrm{s}\right)$. The azimuthal velocity is very slow in both heat pipe regions $\left(4.1810^{-5} \mathrm{~m} / \mathrm{s}\right.$ in the evaporator, $3.6610^{-6} \mathrm{~m} / \mathrm{s}$ in the adiabatic and $4.06410^{-5} \mathrm{~m} / \mathrm{s}$ in the condenser region); it has no significant effect in the phase change phenomena. In the condenser region the axial vapor velocity decreases slowly in the centerline region and reach a maximum of about $0.0911 \mathrm{~m} / \mathrm{s}$.

In Fig. 6 and with critical heat flux density $\left(50000 \mathrm{~W} / \mathrm{m}^{2}\right)$ a reverse flow was clearly appeared in the condenser end cap. The heat pipe length was insufficient for the flow field to develop. In condenser region the vapor decreases much slowly in the centerline region and first recirculation flow appears for NZ $=227$ to the end of the condenser region; witch correspond to a condenser length of nearly $0.13 \mathrm{~m}$ in where reverse flow take place. The maximum axial vapor velocity is about $0.9544 \mathrm{~m} / \mathrm{s}$ and the maximum reverse axial vapor velocity is -
$0.0368 \mathrm{~m} / \mathrm{s}$. the maximum radial vapor velocity are $0.0087 \mathrm{~m} / \mathrm{s}, 0.004 \mathrm{~m} / \mathrm{s}$ and $0.0495 \mathrm{~m} / \mathrm{s}$ in the evaporator, adiabatic and condenser regions respectively. The maximum azimuthal velocities are $0.0054 \mathrm{~m} / \mathrm{s}, 0.0052$ and 0.0028 in the evaporator, adiabatic and condenser regions respectively. One can see that this velocity is greater than the radial velocity in adiabatic region. It can contribute to the reverse flow in this region. The maximum reverse flow velocity in the condenser for the azimuthal velocity is $-0.0046 \mathrm{~m} / \mathrm{s}$. Note that such visualizations which in three dimensional analyses (see Faghri 1991) can be very useful when modeling heat pipe to see the effect of the heat pipe parameters (wick and vapor properties, heat pipe dimensions, etc...).
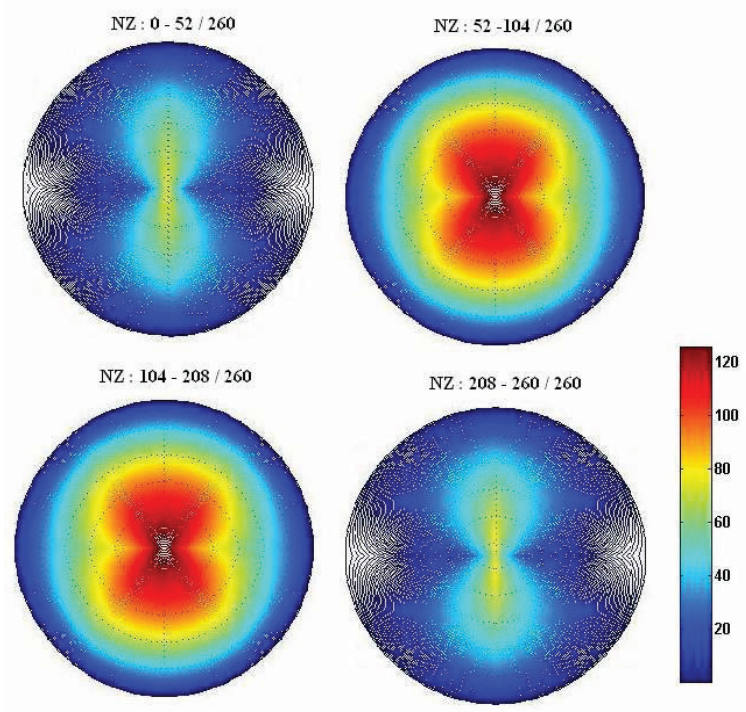

Fig. 5 Dimensional vapor velocity for heat input $\mathrm{Q}=5000 \mathrm{~W} / \mathrm{m}^{2}$
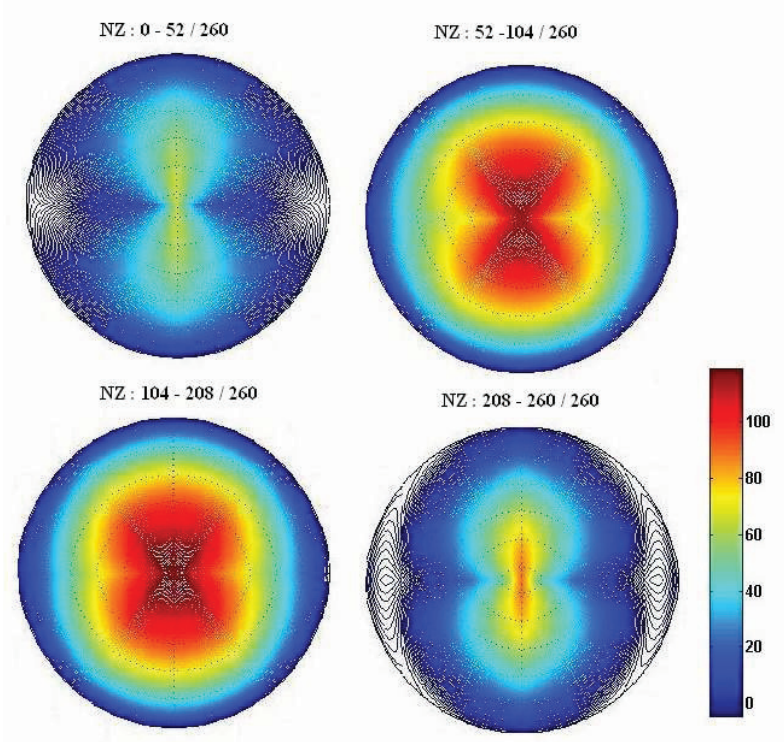

Fig. 6 Dimensional vapor velocity for heat input $Q=50000 \mathrm{~W} / \mathrm{m}^{2}$

Fig.7 shows the liquid circumferential components velocity as seen looking down the pipe axis for heat input/output density of $5000 \mathrm{~W} / \mathrm{m} 2$.

The liquid profile is fully developed in the porous structure. Near the wall/liquid interface the velocity is zero along the heat pipe length because the no-slip condition. The maximum axial liquid velocity is reached in the adiabatic section $\left(-1.234210^{-4} \mathrm{~m} / \mathrm{s}\right)$ and it is the dominant velocity. The uniform blowing/suction about the circumference of the 
liquid-wick/vapor interface can be seen in this Fig.7. For high heat input, the axial liquid velocity increases since it depends on of the heat flux and the injection velocity. Its maximum axial liquid velocity is about $-1.210^{-3} \mathrm{~m} / \mathrm{s}$ (Zhu and Vafai 1999).

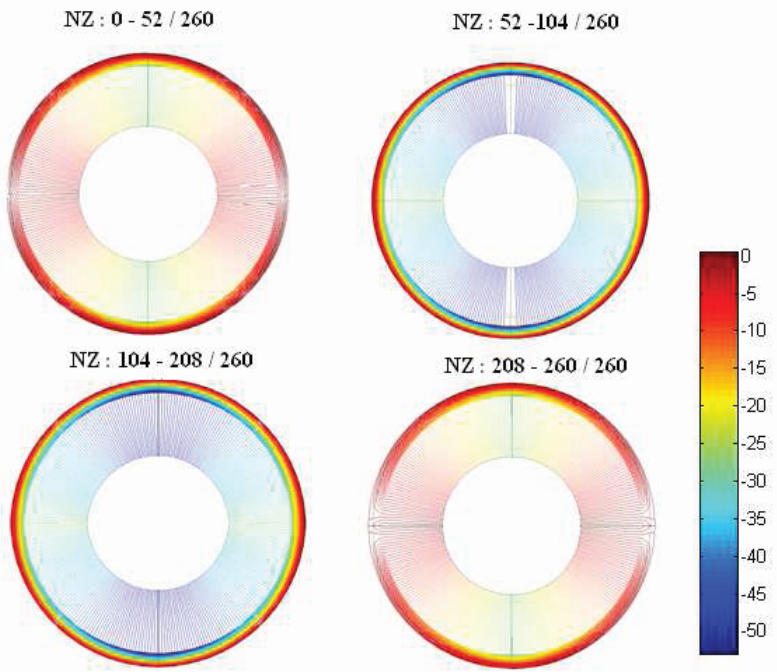

Fig. 7 Dimensional liquid velocity for heat input $\mathrm{Q}=5000 \mathrm{~W} / \mathrm{m}^{2}$
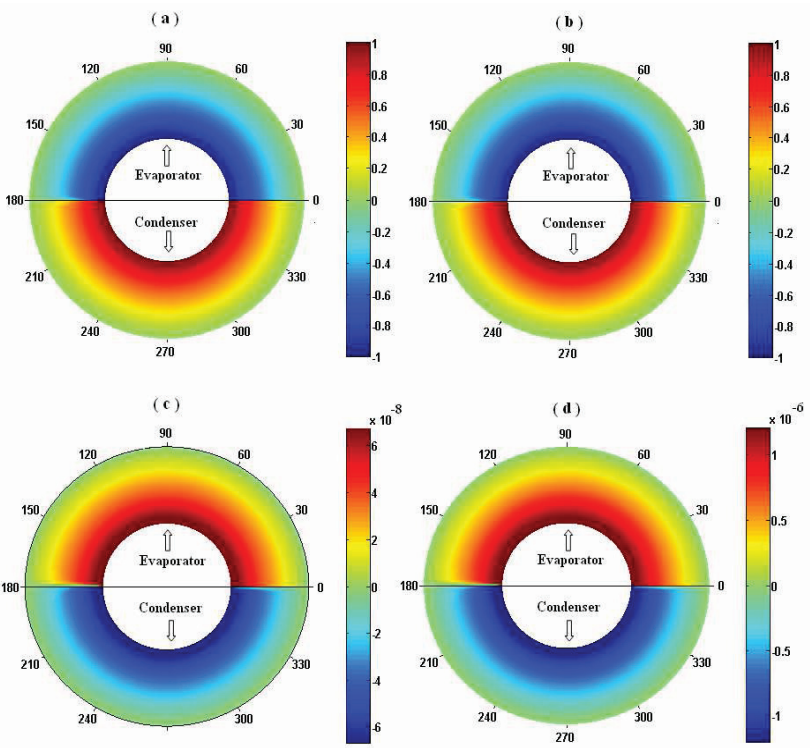

Fig. 8 Dimensional radial velocity components (a, 5000W/ $\left.\mathrm{m}^{2}\right),(\mathrm{b}$, $\left.50000 \mathrm{~W} / \mathrm{m}^{2}\right)$ and azimuthally velocity components $\left(\mathrm{c}, 5000 \mathrm{~W} / \mathrm{m}^{2}\right),(\mathrm{d}$, $50000 \mathrm{~W} / \mathrm{m}^{2}$ ) in the liquid region for two different heat loads.

Fig. 8 shows that the dimensional radial velocity for two heat loads (a-b) in the liquid structure has the same profile but increase nearly linearly when the heat loads increase. For normal heat flux (a) the maximum radial velocities are $1.069210^{-6} \mathrm{~m} / \mathrm{s}$ and $1.05340^{-6} \mathrm{~m} / \mathrm{s}$ in the evaporator and the condenser regions respectively. For critical heat flux (b), they equal to $1.07010^{-5} \mathrm{~m} / \mathrm{s} 1.04910^{-5} \mathrm{~m} / \mathrm{s}$ in the evaporator and the condenser regions respectively. In the adiabatic region, the radial velocity in low (magnitude order of $10^{-8}$ ) since no phase change can occur in this region. One can see that the maximum radial velocity occurs near the interface liquid-vapor and become zero in the interface solid wall / wick structure. As seen looking down the pipe axis, the adiabatic region is removed since no significant effect has been noted and this is because no phase change can occurs. The azimuthal velocity (c-d) increase also when the heat load input increase but remain very low (magnitude order between $10^{-14}$ and $10^{-11}$ ). We can conclude that a two dimensional model in the porous media can describe well the heat pipe wick region since the tangential velocity has no significant effect in this heat pipe situation.
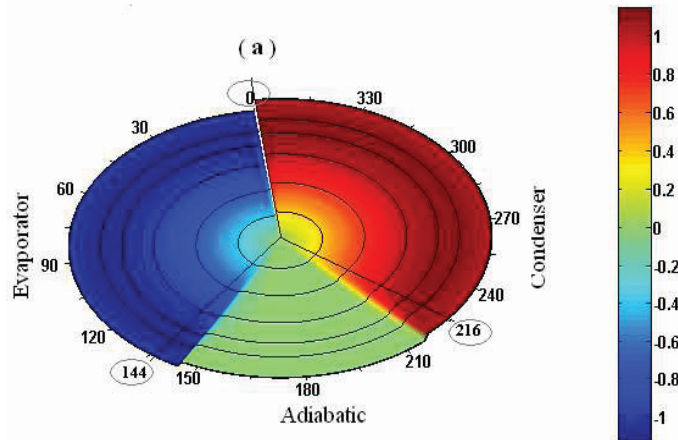

(b)
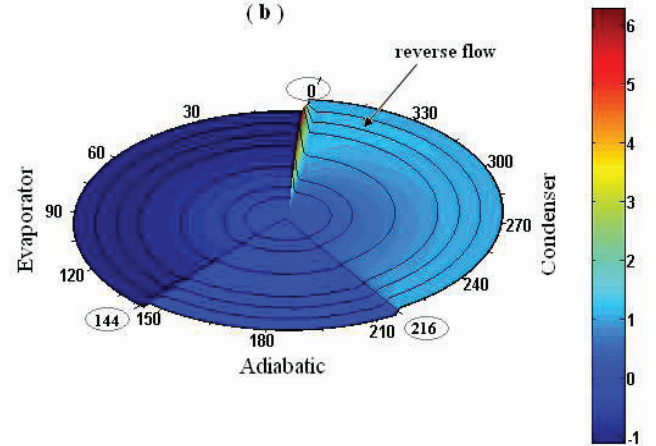

Fig. 9 Dimensional radial velocity components in the vapor region for two different heat loads $\left(\mathrm{a}, 5000 \mathrm{~W} / \mathrm{m}^{2} ; \mathrm{b}, 50000 \mathrm{~W} / \mathrm{m}^{2}\right)$

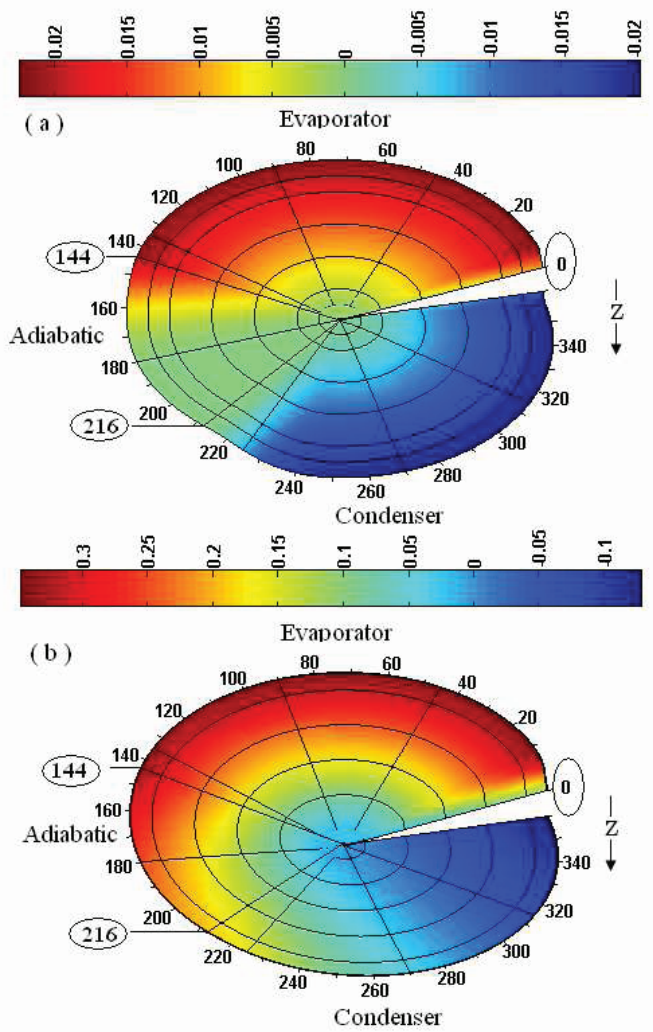

Fig. 9 Dimensional azimuthal velocity components in the vapor region for two different heat loads $\left(\mathrm{a}, 5000 \mathrm{~W} / \mathrm{m}^{2} ; \mathrm{b}, 50000 \mathrm{~W} / \mathrm{m}^{2}\right)$

Note that, the radial velocity depends also on the dimensions and the specific characterizations of the porous media (Eames and al 1997). 
The effect of the heat flux on the radial vapor velocity (a-b) is shown in Fig.9 in both heat pipe regions. The radial vapor velocity in accelerated in the condenser end corner (where a reverse flow occurs) and in the adiabatic region ends (Fig.9 (b)); it can contribute to phase change when the heat pipe is exposed to high heat flux density.

The effect of the azimuthal vapor component velocity $U_{\varphi}$ is shown in the Fig.10 (a) for normal heat flux and Fig.10 (b) for high heat flux. This velocity increases when the heat increase. One can see that the maximum value of $U_{\varphi}$ is reached near the liquid-vapor interface in the vapor region. Its effect on the liquid-vapor interface shape has been not yet well investigated as our knowledge. It becomes greater than the radial velocity in the adiabatic region (a maximum of $0.0052 \mathrm{~m} / \mathrm{s}$ for the azimuthal velocity and a maximum of $0.004 \mathrm{~m} / \mathrm{s}$ for the radial velocity). The azimuthal vapor velocity component discovered to be not zero in the adiabatic region when the heat fluxes increase (Fig. 10 (b)). A phase change can occur in this region because the condenser area becomes incapable to reject the great amount of heat to the surrounding ambient. Also, when the tangential velocity increases, the entrainment phenomena increase at the liquid-vapor interface. This result was detected by Bankston and al $(1972,1973)$ which observed that flow reversal may affect the entrainment limit. We can note also, that when the reverse flow occurred in the end condenser corner of the heat pipe the azimuthal velocity also increase as shown in the Fig.10 (b) when the heat input increase. Note that, in Fig.9 and Fig.10, we are trying to separate the heat pipe regions, so a special visualizing in made taking into account the axial direction on the heat pipe to better visualization. The evaporator region is between 0 and $143^{\circ}$, the adiabatic region is between $144^{\circ}$ and $216^{\circ}$ and the condenser region is between $217^{\circ}$ and $360^{\circ}$.

\section{CONCLUSION}

An originally three-dimensional steady state model for thermal and hydrodynamic transport in heat pipe is developed in cylindrical polar coordinate coupling the three regions in the heat pipe. Kinetic theory of gases is used to account the evaporation and the condensation process at the liquid-vapor interface. A code using the finite volume method was developed to solve the governing equations. The results are compared to two dimensional analytical results for liquid and vapor axial velocities. The good agreement confirms the numerical methods. Following these results, we can confirm that results illustrate well the function of the heat pipe and the circulation of the working fluid inside the heat pipe regions. The maximum circumferential velocity occurred near the liquid vapor interface and increase when the heat loads increase. Results show also that the circumferential velocity is not zero in the adiabatic region when the heat pipe is exposed to higher heat input. This result explain why the at higher heat flux the entrainment limit is affected. The three dimensional analysis yields to more accurate results and better visualizations especially under different external thermal solicitations and boundary conditions, or for different heat pipe characterizations and dimensions. This may be useful in heat pipe modeling and optimization for industrial or academic purpose.

\section{NOMENCLATURE}

$\begin{array}{ll}a_{c c} & \text { accommodation factor } \\ C_{p} & \text { specific heat }(\mathrm{J} / \mathrm{kg} . \mathrm{K}) \\ C_{F} & \text { Ergun's constant }=0.55 \\ h_{f g} & \text { latent heat }(\mathrm{KJ} / \mathrm{kg}) \\ K & \text { permeability }\left(\mathrm{m}^{2}\right) \\ L & \text { heat pipe length }(\mathrm{m}) \\ P & \text { pressure }(\mathrm{Pa}) \\ Q & \text { heat flux density }\left(\mathrm{W} / \mathrm{m}^{2}\right) \\ r & \text { radial coordinate }(\mathrm{m}) \\ r_{s} & \text { average sphere radius }=2.110^{-5} \mathrm{~m}\end{array}$

$\begin{array}{ll}r_{c} & \text { contact radius }(\mathrm{m}) \\ T & \text { temperature }(\mathrm{K}) \\ U & \text { velocity }(\mathrm{m} / \mathrm{s}) \\ V_{i} & \text { injection velocity }(\mathrm{m} / \mathrm{s}) \\ z & \text { axial coordinate }(\mathrm{m})\end{array}$

Greek Symbols

$\alpha \quad$ thermal diffusivity $\left(\mathrm{m}^{2} / \mathrm{s}\right)$

$\varepsilon \quad$ porosity

$\varphi \quad$ azimuthal angle (rad)

$\lambda \quad$ thermal conductivity $(\mathrm{W} / \mathrm{m} . \mathrm{K})$

$\mu \quad$ fluid absolute viscosity $(\mathrm{kg} / \mathrm{m} . \mathrm{s})$

$\rho \quad$ fluid density $\left(\mathrm{kg} / \mathrm{m}^{3}\right)$

$\sigma \quad$ surface tension (Pa.m)

$\begin{array}{ll}\begin{array}{ll}\text { Subscripts } \\ \text { eff }\end{array} & \text { effective } \\ i & \text { injection, interface } \\ l, v, s & \text { liquid, vapor, solid wall } \\ 0 & \text { reference } \\ \text { sat } & \text { saturation } \\ w & \text { wick }\end{array}$

\section{REFERENCES}

Deverall, J.E., Kemme, J.E., and Florschuetz, L.W., 1970, "Sonic Limitations and Startup Problems of Heat Pipes," LA-4518. Doit $W-7405-E N G-36$.

Issacci, F., Catton, I., Ieiss, A., and Ghoniem, N.M., 1988, "Analysis of Heat Pipe Vapor Dynamics," Proc. 25th ASME National Heat Transfer Conf., Vol. 1, pp. 361-365.

http://dx.doi.org/10.1016/10.1080/00986448908940349

Ooigen, H. V. and Hoogendoorm, C. J., 1979, Vapor Flow Calculations in a Flat-Plate Heat Pipe", AIAA J., 17, No. 11, pp 1251-1259.

http://dx.doi.org/0.2514/3.61306

Bankston, C. A. and Smith, H. J., 1972,"Incompressible Laminar Vapor Flow in Cyliderical Heat Pipes", ASME Paper No. 71-WA,HT-15.

Bankston, C. A. and Smith, H. J., 1973 "Vapor Flow in Cylindrical Heat Pipes':, J. Heat Transfer, 95, no. 8, pp 371-376.

http://dx.doi.org/10.1115/1.3450066

A.Faghri., 1991, "Analysis of Frozen Startup of High - Temperature Heat Pipes and Three Dimensional Modeling of Block -Heated Heat Pipes, "Defense Technical Information Center.

N. Zhu and K. Vafai., 1998, "Vapour and Liquid Flow in an Asymmetric Flat Plate Heat Pipe: A Three Dimensional Analytical and Numerical Investigation," Int. J. Heat Mass Transfer, Vol. 41, No. 1, pp. 159-174.

\section{http://dx.doi.org/10.1016/S0017-9310(97)00075-6}

U. Vadakkan, J.Y. Murthy, S.V. Garimella., 2003, "Transient analysis of flat heat pipes," in: Proceedings of the ASME Summer Heat Transfer Conference, July 21-23, LasVegas, Nevada.

U. Vadakkan, S.V. Garimella, J.Y. Murthy, 2004, "Transport in flat heat pipes at high fluxes from multiple discrete sources," ASME J. Heat Transfer26, 347-354

http://dx.doi.org/10.1115/1.1737773

G. Carbajal, C.B. Sobhan, G.P. 2007 “Bud” Peterson, D.T. Queheillalt , Haydn N.G. Wadley," A quasi-3D analysis of the thermal 
performance of a flat heat pipe," International Journal of Heat and Mass Transfer 50, 4286-4296.

http://dx.doi.org/10.1016/j.ijheatmasstransfer.2007.01.057

B. Xiao, A. Faghri, 2008, "A three-dimensional thermal-fluid analysis of flat heat pipes," Int. J. Heat Mass Transfer 51, 3113-3126.

http://dx.doi.org/10.1016/j.ijheatmasstransfer.2007.08.023

R. Ranjan, J. Y. Murthy, S. V. Garimella, U. Vadakkan, 2001, “A numerical model for transport in flat heat pipes considering wick microstructure effects", Int. J. Heat and Mass Transfer 54,153-168.

http://dx.doi.org/10.1016/j.ijheatmasstransfer.2010.09.057

Chi,S. W. 1976, Heat Pipe Theory and Practice. Hemisphere Publishing Company, Washington, D.C., New York, McGraw-Hill Book Co., 1976. 256 p.

A.Faghri, 1995,"Heat Pipe Science and Technology", Taylor and Francis, PP. 136-138, pp. 268-281.
Eames, I. W., Marr, N. J., and Sabir, H., 1997,'The evaporation coefficient of water",: a review, int. journal heat and mass transfer, 40, 29632973

http://dx..doi.org/10.1016/S0017-9310(96)00339-0

N. Zhu., K. Vafai, 1999,“Analysis of cylindrical heat pipes incorporating the effects of liquid-vapor coupling and non-Darcian transport a closed form solution," Int. J. Heat Mass Transfer 37 34053418 .

http://dx.doi.org/10.1016/S0017-9310(99)00017-4

J.M.Tournier, M.S. El-Genk, 1994, "A heat pipe transient analysis model," Int. J. Heat Mass Transfer 37 (1994) 753-762.

http://dx.doi.org/10.1016/0017-9310(94)90113-9 